\title{
Information and Communication Technology-Based Education Planning and Attitude of College Students
}

\author{
https://doi.org/10.3991/ijim.v15i04.20365
}

Yamunah Vaicondam $(\bowtie)$

Segi University, Petaling Jaya, Malaysia

yamunahvaicondamesegi.edu.my

Sanil S Hishan

Azman Hashim International Business School (AHIBS),

Universiti Teknologi Malaysia, Kuala Lumpur, Malaysia

Samina Begum

Abbottabad University of Science and Technology, Khyber Pakhtunkhwa, Pakistan

Muhammad Hassan

Abbottabad University of Science and Technology, Khyber Pakhtunkhwa, Pakistan Universiti Malaysia Kuala Lumpur Malaysia

\begin{abstract}
The ubiquity of Information and Communication Technology (ICT) in every school framework in the world has become a trend. With ASEAN integration problems in 2015, can fresh and younger HEI's and their students cope with this trend? The goal of this analysis is to decide the preparedness and role of new HEI students in the field of ICT education. In this study a concise template utilizing a researcher-made questionnaire $(\alpha=.971)$ was used. The research findings show that students at college have a optimistic declaration ('agreement') on ICT use in education $(x=3.71 ; S=.75)$. This was also shown that sex greatly affects the mindset of students $(\mathrm{z}=3.91, \mathrm{p}=.00)$, where male attitudes are higher $(x=3.91)$ than female attitudes $(x=3.61)$. Moreover, it demonstrates that preparedness for ICT in general has little to do with the mindset of students towards the usage of ICT in school. Nonetheless, there is a important marginal positive association between ICT access and an attitude of significance to $0.05(\mathrm{r}=.15 ; \mathrm{p}=.002$; single-tailed), which suggests that the more a student gets introduced to ICT, the more he develops his attitude to ICT education. It was believed that ICT-based curriculum can be readily adopted and modified for the next several years by complete ICT adoption as the current educational framework. Current and younger HEIs will also spend more in ICT Accessibility and Connectivity to further boost ICT-based awareness and preparedness.
\end{abstract}

Keywords - Schooling Focused on ICT, ICT Mindset, ICT Planning 


\section{Introduction}

The usage of computer technology became a common trend. From the development of the wheel, to the creation of telephone and the uncovering of one of the most significant inventions - the Internet. Much like the announcement of the machine as the Individual of the Year foreshadowed the ubiquity of the device in daily life by Time Magazine in 1982, we agree that this iconic recognition is precursor to significant technical and cultural improvements over the years. Digital technology is becoming more and more omnipresent and interactive. (www.computer.org, 2010) After machine adoption in the 1980s, rapid development has been witnessed in South Asia, in particular in Bhutan, a third-world nation. Pradhan (2003a) announced that Bhutan had 1,130 Internet connections which increased to 3,036 in just two years in 2005 (Bhutan's Government, 2006, as quoted in Baggaley and Belawati (2010a). To support this, an report reported that as from $2010,40 \%$ of adults 30 and older, $72 \%$ of young adults and $73 \%$ of adolescents were on social networking platforms, with Facebook time spending year-on-year increasing by $566 \%$. In 2009, Twitter users created 35 million tweets a day. Wikipedia has more than 12 million registered users and over 3 million pages of content. There are several instances of dynamic web-based societies and innovative types of interactive computing technologies, including prediction markets, mutual screening, virtual bookmarking, electronic trading and peer development mechanisms in the networks (www.computer.org, 2010). Indeed, these further prove that ICT, specifically the Internet, is genuinely a 21 st century global network-the first completely modern technology to grow in almost one century.

\subsection{ICT and education}

Kozma (2010) stated that the digital and communications systems are changing every aspect of society in the 21 st century: the economy, office, home, retail, government, healthcare and even schooling. But Kozma argues that ICTs are late relative to others and according to Mr Kozma, educational programs work as they did at the beginning of the 20thcentury (see Roblyer and Doering, 2013a), pointing to improvements made by ICTs on certain issues.

Studies reveal that higher outcomes have been reported in the students 'successes in high-stakes exams. Schools of single-to - one services saw an improvement of 70\% compared of non-one - to-one systems, which contributed to just $69 \%$. However, there was a significantly higher rise of 85 per cent in single-to - one schools that utilized "performance measures like routine online formative assessments and the daily participation of teachers in technical learning groups" (Devaney, 2010 in Roblyer and Doering, 2013c).

Similarly, a variety of studies were undertaken in South Asia, primarily in Bhutan, Pakistan and Sri Lanka. The studies showed that ICT is a good resource for rendering research practical and productive because it is used for schooling (Baggaley \& Belawati, 2010b; Jamtsho\&Bullen, 2007; Sangi \& Ahmed, 2007). In Baggaley and Belawati (2010c), Attygale, et.al (2006) indicated that students had a constructive outlook towards and use of ICTs. This facilitates a conceptual change from teacher- 
based to instructional approaches (Baggaley and Belawati) and thereby individualizes instruction, encouraging improved student outcomes. $77 \%$ of students and educators in higher education in Bhutan use ICT approaches in a report by Jamtsho and Bullen (2007b). The study also shows that 80 percent of Pakistani students and educators continue to use ICT in their existing curricula and Wikramanayake, etc. (2007b) reported that $89 \%$ of Sri Lankan students use ICT services in their curricula.

Given the increasing acceptability of ICT in education, governments recognize the necessity for much larger 'mass' access to higher education and further learning and the need to equip national workers with an initial basis and skills of 'lifelong learning' to provide the reaction and flexibility to an increasing rate of change (Roblyer \& Doering, 20). Moreover, researchers argued that ICT was so widespread that the increasing involvement and investments in ICT uses in education around the globe was no longer unexpected (Baggaley and Belawati, 2010f; Pradhan, 2003; Zhang, 2004).

\subsection{Advantages of ICT in education}

The World Wide Web or the Internet is a collection of digital resources, graphics and telecommunications. It has searchable content collections, including digital, virtual, hyperlinked materials and search engines, which enable users locate what students and teachers need from everywhere on the world (Coleman, 2012).

The benefits of ICT are daunting in school. Such problems were grouped into three wide fields by Ali (2003). The first involves engagement in the knowledge society, whilst the second is the effect of ICT on exposure, cost efficiency and education quality, and the third is the manner in which ICT changes the education cycle. The Baggaley and Belawati (2010) concluded that such problems are based on ICT costs that affect transparency and affordability; educators 'training needs; inaccessibility of ICTsupported and internet-provided learning resources that are housed in closed networks. (Ali, 2003).

\subsection{ICT and education in the Philippines}

Through launching a number of programs to introduce ICT in teaching and training, the Philippine government through DepED has shown serious commitment to ICT in education. We also associated with the MDGs and the schooling of all movements. The ICT4E Strategic Strategy came into being in reaction to the need. According to DepED, the usage of ICT in teaching and studying must be followed by the accompanying reform in the school curriculum. A summary of the mindset and readiness of college students on ICTs in new and younger HEIs needs to be studied through different existing studies. With ASEAN integration as a obstacle in 2015, this research aims at the following goals:

1) To decide the degree of preparedness of younger HEI college pupils for ICT education

2) To evaluate the stance of fresh and younger HEI students towards ICT-based education

3) To check that gender and ICT preparations lead to student attitude towards ICTbased education. 


\section{Method}

This thesis used the concise, empirical, correlative, research design. The 392 students at a chosen university were sampled via stratified random sampling process. The university students come from various specialization areas or backgrounds. Data collection was conducted with an modified sample survey $(a=.971)$ from various ICT studies in Asian countries.

The results were interpreted by this scale on ICT-based training attitude: 4.20-5.00Strongly agreed; 3.40-4.19-Agree; $2.60-3.39-$ Not in conflict or agreement; $1.80-2.59$ Disagree 1.00-1.79-Far from disagreement.

\section{$3 \quad$ Results and Discussion}

\subsection{The level of ICT penetration}

The study shows that the weighted mean when asking whether respondents or participants perceive their access to ICT is $\mathrm{x}=4.59$ and standard deviation is 1.35 . This is expressed as 1-6 from time to time revealed. If ICT is fully integrated into the current HEI education system, the outcomes will be quite promising because students no longer have the difficulties of adjusting to the ICT conditions permeated by the educational system of a nation like the Philippines and the ASEAN countries.

\subsection{ICT-based education preparedness}

"Preparedness" in this research relates to exposure to technology, computer usage purposes, college or study experience, form of device typically used, level of use of ICTs and influences which can promote the use of ICTs in school.

Table 1. Data Frequency Distribution (N=392)

\begin{tabular}{|l|c|c|}
\hline \multicolumn{1}{|c|}{ Indicators } & f & \% \\
\hline Use own personal computer & 296 & 75.5 \\
\hline Use computer of other people/classmates/relatives & 31 & 7.9 \\
\hline Use computer from shop/internet cafe & 59 & 15.1 \\
\hline Use computer in school & 6 & 1.5 \\
\hline
\end{tabular}

Table 1 says that the majority of university students use their own personal computers ( 296 or $75.5 \%$ ) when it comes to using tests. With the emergence of the Internet, computer usage became huge, as shown by a national study of the Synovate Media Atlas from July 2008 to June 2009 which showed that internet access is 40 percent in the Philippines. Although in the analysis it was not specified that children use their own computers to access them, easy access to the output of computers makes it easy to access the internet. However, 54 percent of people access the internet from an Internet cafe (54 percent) compared to home ( 47 percent) was noticed in the same report. 
Very common reasons for using ICT

Table 2. Most Common Reasons of ICT using Frequency Distribution (N=392)

\begin{tabular}{|l|c|c|}
\hline \multicolumn{1}{|c|}{ Indicators } & f & \% \\
\hline Use computer in studies/work & 218 & 55.6 \\
\hline Use computer in games/recreation & 68 & 17.3 \\
\hline Use computer in socialization with friends and classmates & 106 & 27 \\
\hline
\end{tabular}

Table 2 demonstrates succinctly student competence in ICT or machine usage. Most college students use machines in research or work (218 or 55,6 percent), or also in games and entertainment (68 or 17,3 percent), rather than in socialization with peers and classmates (106 or 27 percent). In its study to UNICEF, the Asian Institute of Journalism has stated that school children primarily use the Internet for networking purposes to send / receive texts, link friends and engage in e-groups and networks. According to the AIJC, the internet is seen as a powerful educational resource, particularly among primary school children. They understand the value of the Internet through their usage of the Internet for school research.

Table 3. Research Planning Frequency Distribution $(\mathrm{N}=392)$.

\begin{tabular}{|l|c|c|}
\hline \multicolumn{1}{|c|}{ Indicators } & f & \% \\
\hline Have formal course on computers/ICT & 83 & 21.2 \\
\hline Have short course on computers/ICT & 141 & 36 \\
\hline No formal nor short course on computers or ICT & 164 & 41.8 \\
\hline
\end{tabular}

The study also shows that students do not need structured machine or ICT instruction to use them. 164 or $41.8 \%$ of the 392 respondents have no computer or ICT formal or short course, 141 or $36 \%$ have a short course, and 83 or $21.2 \%$ have a structured computer or ICT course. The AIJC study shows that, despite a lack of formal training, school pupils are very interested in computers and ICTs.

Table 4. Internet Connectivity Frequency Distribution (N=392)

\begin{tabular}{|l|c|c|}
\hline \multicolumn{1}{c|}{ Indicators } & f & \% \\
\hline Computer with Internet & 360 & 91.8 \\
\hline Computer without Internet & 31 & 7.9 \\
\hline
\end{tabular}

Table 4 shows how students perceive ICT as most of them have Internet access machines (360 or 91.8 percent). For heavily digitized communities, machines without an Internet connection become irrelevant and useless. In libraries and bookstores, educational materials must not be displayed, but can be obtained via the internet.

Table 5. ICT Using Frequency Distribution $(\mathrm{N}=392)$

\begin{tabular}{|l|c|c|}
\hline \multicolumn{1}{|c|}{ Indicators } & f & \% \\
\hline Less than once a month & 35 & 8.9 \\
\hline At least once a month & 54 & 13.8 \\
\hline
\end{tabular}


The research also reveals that students use ICT at least once a week (294 or 75 percent) to read, socialize or exercise. Nevertheless, people often use the machine at least once a month (54 or $13.8 \%$ ), but fewer than once a month (35 or $8.9 \%$ ). The report reveals how omnipresent ICTs are in schooling. The research also reveals that students use ICT at least once a week (294 or 75 percent) to read, socialize or exercise. Nevertheless, people often use the machine at least once a month (54 or $13.8 \%$ ), but fewer than once a month (35 or $8.9 \%$ ). The report reveals how omnipresent ICTs are in schooling.

Table 6. Frequency Distribution of ICT-Enhancing Variables (N=392)

\begin{tabular}{|l|c|c|}
\hline \multicolumn{1}{|c|}{ Indicators } & f & \% \\
\hline Easier access at school & 218 & 55.6 \\
\hline Free and cheap access & 65 & 16.6 \\
\hline Easier access at home & 85 & 21.7 \\
\hline Free/cheaper lessons & 20 & 5.1 \\
\hline
\end{tabular}

Table 6 reveals that better school exposure enables the students to use ICT (218 or 55.6 percent). Of necessity, since students spend most of their time at school than at home, it is extremely important for a student to have access to an ICT facility.

\subsection{ICT-based curriculum mindset}

Table 7. ICT-Based Education Perceptions $(\mathrm{N}=392)$

\begin{tabular}{|l|l|l|}
\hline \multicolumn{1}{|c|}{ Indicators } & Mean & $\begin{array}{c}\text { Qualitative Inter- } \\
\text { pretation }\end{array}$ \\
\hline 1. Easier school exposure & 3.95 & Agree \\
\hline 2. Safe and reasonable exposure & 3.41 & Agree \\
\hline 3. Easier home entry & 3.90 & Agree \\
\hline 4. Free / cheaper lessons & 3.87 & Agree \\
\hline 5.You don't have to be a programmer to interact with machines. & 3.38 & Neither disagree nor \\
\hline 6. Interactive and insightful ICT-enabled learning. & 3.75 & Agree \\
\hline 7. Email is an effective way for teacher and student to communicate. & 3.73 & Agree \\
\hline 8. Social networking is an important way of teaching and learning connectivity. & 3.72 & Agree \\
\hline 9. The computer / internet is easy to use to study. & 3.76 & Agree \\
\hline 10. ICTs improve research incentive. & 3.68 & Agree \\
\hline 11. ICT makes my classes more appealing. & 3.72 & Agree \\
\hline 12.ICT leads to increasing my productivity. & 3.71 & Agree \\
\hline 13.For my research, ICT is inexpensive. & 3.70 & Agree \\
\hline Overall & 3.71 & Agree \\
\hline
\end{tabular}

Furthermore, the study shows that students agree on virtually all positive things about ICT and computers ( $\mathrm{x}=3.71$, S.D. $=.75)$ except that you do not need intelligent or "conscious" things to work with ICT or computers, as students are not in agreement or disagree with it $(\mathrm{x}=3.38, \mathrm{SD}=1.12)$. As a consequence, some students feel that 
when you deal with machines, you ought to be a "machine," whereas others don't feel in it. But all are in line (about 3.40-4.19) to suggest that ICTs are more easiness to learn; ICT's are more experienced than books; ICTs will help you learn; machines are important instructional tools; ICT-enabled research is engaging and interesting; email is an efficient way of communicating about teachers and students; social networking is an influence.

\subsection{The disparity in mood is classified by gender}

Table 8. Overview of the Personality Gap According to Gender

\begin{tabular}{|l|c|c|c|}
\hline \multicolumn{1}{|c|}{ Indicators } & z-value & p- value & Q.I. \\
\hline 1. Easier school exposure & 2.067 & .039 & $\mathrm{~S}$ \\
\hline 2. Safe and reasonable exposure & 4.373 & .000 & $\mathrm{~S}$ \\
\hline 3. Easier home entry & 2.382 & .018 & $\mathrm{~S}$ \\
\hline 4. Free / cheaper lessons & 3.347 & .001 & $\mathrm{~S}$ \\
\hline 5.You don't have to be a programmer to interact with machines. & 2.244 & .025 & $\mathrm{~S}$ \\
\hline 6. Interactive and insightful ICT-enabled learning. & 4.236 & .000 & $\mathrm{~S}$ \\
\hline 7. Email is an effective way for teacher and student to communicate. & 3.675 & .000 & $\mathrm{~S}$ \\
\hline 8. Social networking is an important way of teaching and learning connectivity. & 3.217 & .001 & $\mathrm{~S}$ \\
\hline 9. The computer / internet is easy to use to study. & 2.211 & .028 & $\mathrm{~S}$ \\
\hline 10. ICTs improve research incentive. & 2.604 & .010 & $\mathrm{~S}$ \\
\hline 11. ICT makes my classes more appealing. & 2.173 & .030 & $\mathrm{~S}$ \\
\hline 12.ICT leads to increasing my productivity. & 3.335 & .001 & $\mathrm{~S}$ \\
\hline 13.For my research, ICT is inexpensive. & 1.609 & .108 & $\mathrm{~S}$ \\
\hline Overall & 3.912 & .000 & $\mathrm{~S}$ \\
\hline
\end{tabular}

Legend: Q.I.- Qualitative Interpretation; NS- There is no significant difference; S- There is a significant difference

Table 8 illustrates how class affect student attitudes towards ICT-based schooling, because the optimistic overall outlook ranges considerably as class is taken into consideration $(\mathrm{z}=3.91, \mathrm{p}=.00)$. Results show that the male disposition is more favorable than the female $(x=3.91)$ in this sample, so this is statistically important. There are possible explanations, one of which is that people are physically more sensitive than women. In a survey by Synovate Web Atlas (2008), quoted in its report to UNICEF by the Asian Center of Journalism and Communication, Internet non-users are primarily female children participating in public elementary schools. However, there is no gender difference when it comes to internet connectivity because there is an fair separation between male and female Internet users with the exception of Mindanao. But as far as the early usage of ICT is concerned, kids are earlier consumers than females, as machines are often considered to be more drawn to devices than females by toys and young people. This may clarify the small "gap" between men and women in ICTbased schooling. 


\subsection{Disparity in mindset in terms of preparation}

Table 9. Disposition Gap According to Computer Access

\begin{tabular}{|l|c|c|c|}
\hline \multicolumn{1}{|c|}{ Indicators } & F-value & p-value & Q.I. \\
\hline 1. Easier school exposure & .92 & .433 & NS \\
\hline 2. Safe and reasonable exposure & .77 & .514 & NS \\
\hline 3. Easier home entry & 1.04 & .377 & NS \\
\hline 4. Free / cheaper lessons & 1.58 & .195 & NS \\
\hline 5.You don't have to be a programmer to interact with machines. & .25 & .862 & NS \\
\hline 6. Interactive and insightful ICT-enabled learning. & .78 & .506 & NS \\
\hline 7. Email is an effective way for teacher and student to communicate. & .94 & .423 & NS \\
\hline 8. Social networking is an important way of teaching and learning connectivity. & .25 & .861 & NS \\
\hline 9. The computer / internet is easy to use to study. & .67 & .572 & NS \\
\hline 10. ICTs improve research incentive. & 1.15 & .330 & NS \\
\hline 11. ICT makes my classes more appealing. & .93 & .428 & NS \\
\hline 12.ICT leads to increasing my productivity. & 1.70 & .166 & NS \\
\hline 13.For my research, ICT is inexpensive. & 1.34 & .262 & NS \\
\hline Overall & .82 & .484 & NS \\
\hline
\end{tabular}

Table 9 reveals that students 'behaviors will not differ greatly when it comes to internet access. This indicates that if students have their own computers or use school computer systems, internet cafes, peers and families, their attitude towards ICT is the same and mostly optimistic.

Table 10. Attitude Variations According to Most Common Computer Use Explanations

\begin{tabular}{|c|c|c|c|}
\hline Indicators & F-value & p- value & Q.I. \\
\hline 1. Easier school exposure & .46 & .63 & NS \\
\hline 2. Safe and reasonable exposure & 2.92 & .06 & NS \\
\hline 3. Easier home entry & .51 & .60 & NS \\
\hline 4. Free / cheaper lessons & .07 & .93 & NS \\
\hline 5.You don't have to be a programmer to interact with machines. & .94 & .39 & NS \\
\hline 6. Interactive and insightful ICT-enabled learning. & .36 & .70 & NS \\
\hline 7. Email is an effective way for teacher and student to communicate. & .64 & .53 & NS \\
\hline 8. Social networking is an important way of teaching and learning connectivity. & 2.39 & .09 & NS \\
\hline 9. The computer / internet is easy to use to study. & 1.69 & .19 & NS \\
\hline 10. ICTs improve research incentive. & 1.80 & .17 & NS \\
\hline 11. ICT makes my classes more appealing. & .16 & .85 & NS \\
\hline 12.ICT leads to increasing my productivity. & 3.07 & .05 & $\mathbf{S}$ \\
\hline 13.For my research, ICT is inexpensive. & 1.56 & .21 & NS \\
\hline Overall & .77 & .46 & NS \\
\hline
\end{tabular}

Likewise, as with other specific purposes of computer usage, figures reveal that there are no substantial discrepancies between students 'attitudes generally, although clustered by popular grounds of computer usage $(\mathrm{F}=.77 ; \mathrm{p}=.46)$. These vary, except that the measure questioning if ICT is helping to improve student efficiencies 
$(\mathrm{F}=3.07 ; \mathrm{p}=.05)$, suggests a major variation in attitude rates. It means that ICT-based schooling is very convenient with those who research for computers and for training, as figures indicate that the weighted average for this category is 4.14 for attitudes over 3.68 for those who use computers and ICT for socialization. Moreover, apart from the effect of ICT on efficiency, what is interesting is the second closest with the probability value of.06 even if it is not statistically significant; that is to say that you could learn from computers or other technology than books. Past studies in certain Asian countries such as Bhutan have shown that, given the invasion of ICTs, many still consider books as the primary source of information. Students score this metric relatively high 3.41, but when clustered together for machine usage purposes it is not statistically relevant.

Table 11. Attitude Variations According to the Plans for the Analysis

\begin{tabular}{|l|c|c|c|}
\hline \multicolumn{1}{|c|}{ Indicators } & F-value & p- value & Q.I. \\
\hline 1. Easier school exposure & .06 & .95 & NS \\
\hline 2. Safe and reasonable exposure & 1.49 & .23 & NS \\
\hline 3. Easier home entry & .67 & .51 & NS \\
\hline 4. Free / cheaper lessons & .06 & .95 & NS \\
\hline 5.You don't have to be a programmer to interact with machines. & .14 & .87 & NS \\
\hline 6. Interactive and insightful ICT-enabled learning. & .01 & .99 & NS \\
\hline 7. Email is an effective way for teacher and student to communicate. & 1.40 & .25 & NS \\
\hline 8. Social networking is an important way of teaching and learning connectivity. & 1.74 & .18 & NS \\
\hline 9. The computer / internet is easy to use to study. & 1.64 & .20 & NS \\
\hline 10. ICTs improve research incentive. & 2.31 & .10 & NS \\
\hline 11. ICT makes my classes more appealing. & 2.06 & .13 & NS \\
\hline 12.ICT leads to increasing my productivity. & .96 & .38 & NS \\
\hline 13.For my research, ICT is inexpensive. & .94 & .39 & NS \\
\hline Overall & 1.23 & .29 & NS \\
\hline
\end{tabular}

Table 11 indicates that computer studies or other forms of academic learning may not influence students 'attitude towards ICT-based training because only in one measure no substantial change was found, even more than the overall attitude. The smallest of them is .10 but that is twice as big as the .05 mark. It measure sends a message that ICT enhances research encouragement, but is not important. ICT preparation cannot really motivate a pupil to have a good outlook towards ICT education.

Table 12 shows that the mean average will not indicate a big difference $(z=.78$; $\mathrm{p}=.44$ ) when categorized according to the kinds of device used - with or without the internet access, but there is a substantial variation in certain measures. There is, for example, a major gap between how email administrators and Phone consumers react to the claim that it's easy to know by using ICT $(z=3.27 ; p=0.003)$. Basically, there are variations, as this metric has a higher score $(x=4.04)$ for those with an internet link and a lower score has been given for those without an Internet connection $(x=3.03)$ 
Table 12. Disposition Discrepancies According to Device Styles Used

\begin{tabular}{|l|c|c|c|}
\hline \multicolumn{1}{|c|}{ Indicators } & F-value & p- value & Q.I. \\
\hline 1. Easier school exposure & 3.27 & .003 & S \\
\hline 2. Safe and reasonable exposure & 1.48 & .15 & NS \\
\hline 3. Easier home entry & 2.42 & .021 & S \\
\hline 4. Free / cheaper lessons & 1.93 & .062 & NS \\
\hline 5.You don't have to be a programmer to interact with machines. & .94 & .35 & NS \\
\hline 6. Interactive and insightful ICT-enabled learning. & 2.12 & .041 & S \\
\hline 7. Email is an effective way for teacher and student to communicate. & 1.12 & .27 & NS \\
\hline 8. Social networking is an important way of teaching and learning connectivity. & -.48 & .64 & NS \\
\hline 9. The computer / internet is easy to use to study. & .89 & .38 & NS \\
\hline 10. ICTs improve research incentive. & -1.79 & .083 & NS \\
\hline 11. ICT makes my classes more appealing. & -1.05 & .302 & NS \\
\hline 12.ICT leads to increasing my productivity. & -1.32 & .196 & NS \\
\hline 13.For my research, ICT is inexpensive. & -3.08 & .004 & S \\
\hline Overall & .781 & .44 & NS \\
\hline
\end{tabular}

Similarly, a substantial contrast is observed for the sentence that states, "A machine will help you understand" $(\mathrm{z}=2.42 ; \mathrm{p}=0.021)$. The same was said with the statements "ICT-friendly learning is immersive and informative" $(\mathrm{z}=2.12 ; \mathrm{p}=.041)$ and "ICT is accessible for my research." Of example, Internet connectors rank the score higher than those without link. The research only reveals how the Internet has influenced people's minds. Roblyer and Doering (2013) stressed how the Internet transformed the literacy and schooling world drastically.

Table 13.

Disposition Discrepancies According to Device Usage Level

\begin{tabular}{|c|c|c|c|}
\hline Indicators & F-value & p- value & Q.I. \\
\hline 1. Easier school exposure & 2.48 & .09 & NS \\
\hline 2. Safe and reasonable exposure & 1.19 & .31 & NS \\
\hline 3. Easier home entry & 1.17 & .31 & NS \\
\hline 4. Free / cheaper lessons & 1.46 & .24 & NS \\
\hline 5.You don't have to be a programmer to interact with machines. & .10 & .90 & NS \\
\hline 6. Interactive and insightful ICT-enabled learning. & .006 & .99 & NS \\
\hline 7. Email is an effective way for teacher and student to communicate. & 1.14 & .32 & NS \\
\hline 8. Social networking is an important way of teaching and learning connectivity. & 2.55 & .08 & NS \\
\hline 9. The computer / internet is easy to use to study. & 1.43 & .24 & NS \\
\hline 10. ICTs improve research incentive. & 2.86 & .06 & NS \\
\hline 11. ICT makes my classes more appealing. & 1.17 & .31 & NS \\
\hline 12.ICT leads to increasing my productivity. & 1.74 & .18 & NS \\
\hline 13.For my research, ICT is inexpensive. & .83 & .44 & NS \\
\hline Overall & .54 & .59 & NS \\
\hline
\end{tabular}

The duration of the usage of the machine is not a consideration in determining the attitude towards ICT-based learning $(\mathrm{F}=.54 ; \mathrm{p}=.59)$. What implies, though, is the observation that the subject is influenced by $\operatorname{ICT}(\mathrm{F}=2.86 ; \mathrm{p}=.06)$, and that is not statistically important. If ICTs or machines are used once a week, once a month, once a 
year or per day, machine attitudes do not differ. This could be because people do not often use ICT for their purposes of study or science, even though the highest aim of using ICT is to carry out scholarly tasks, such as studying, but other ICT users may still use the Internet for socialization and entertainment. In fact, this often highlights the cliché regarding the value of consistency over quantity. Ten hours of gaming do not equate an hour of mere work where education efficiency is the only standard.

Table 14. Personality Discrepancies According to Device Use Variables

\begin{tabular}{|c|c|c|c|}
\hline Indicators & F-value & p-value & Q.I. \\
\hline 1. Easier school exposure & 2.33 & .07 & $\mathrm{NS}$ \\
\hline 2. Safe and reasonable exposure & 1.29 & .28 & NS \\
\hline 3. Easier home entry & 1.95 & .12 & NS \\
\hline 4. Free / cheaper lessons & .78 & .51 & NS \\
\hline 5.You don't have to be a programmer to interact with machines. & 2.5 & .06 & NS \\
\hline 6. Interactive and insightful ICT-enabled learning. & 2.59 & .05 & $\mathbf{S}$ \\
\hline 7. Email is an effective way for teacher and student to communicate. & .19 & .90 & NS \\
\hline 8. Social networking is an important way of teaching and learning connectivity. & .69 & .56 & NS \\
\hline 9. The computer / internet is easy to use to study. & 1.29 & .28 & NS \\
\hline 10. ICTs improve research incentive. & 1.42 & .24 & NS \\
\hline 11. ICT makes my classes more appealing. & .93 & .43 & NS \\
\hline 12.ICT leads to increasing my productivity. & 1.53 & .21 & NS \\
\hline 13.For my research, ICT is inexpensive. & 1.37 & .25 & $\mathrm{NS}$ \\
\hline Overall & 2.00 & .11 & $\mathrm{NS}$ \\
\hline
\end{tabular}

Table 14 represents correctly the assumption that the degree of ICT-based education mindset is usually not influenced by influences that enable students to use ICT in their studies $(\mathrm{F}=2 ; \mathrm{p}=.11)$, except for one measure, that ICT-friendly learning is engaging and responsive. Furthermore, the amount of mindset of those who choose the 'easy and inexpensive exposure to ICT' component is higher $(\mathrm{x}=4.0)$ than those who chose the facilitative exposure component at home or school $(x=3.7)$. This variation is statistically important $(\mathrm{F}=2.59 ; \mathrm{p}=.05)$. The indication that you don't need to be 'conscious' to deal with computers comes in second $(\mathrm{F}=2,50 ; \mathrm{p}=, 06)$ given its insignificance, and 'It's simple to know through ICT' $(F=2,33 ; p=, 07)$ is sixth.

\subsection{The connection between perception and actions}

The overall picture indicates a marginally marginal positive correlation between ICT sensitivity and ICT-based training at ICT stage $05(\mathrm{r}=0.15, \mathrm{p}=.002$; all one and two-tailed tests). In fact, almost all statement metrics have the same degree of association, excluding three statement(s): "ICTs improve research incentive $(r=0.07 ; \mathrm{p}=.08) ; "$ "ICTs make my lessons more exciting $(\mathrm{r}=.06 ; \mathrm{p}=.13) ;$ " and "ICT is economical for my studies," ( $\mathrm{r}=.03 ; \mathrm{p} .30)$. It suggests that the further exposed a student becomes to ICT during research, the more changed his / her attitude towards ICT-based schooling. 
Table 15. Exposure and Attitude Partnership

\begin{tabular}{|l|c|c|c|}
\hline \multicolumn{1}{|c|}{ Indicators } & r-value & $\begin{array}{c}\text { p-value } \\
\text { (1-tailed) }\end{array}$ & Q.I. \\
\hline 1. Easier school exposure & .1 & .03 & SC \\
\hline 2. Safe and reasonable exposure & .172 & .000 & SC \\
\hline 3. Easier home entry & .113 & .014 & SC \\
\hline 4. Free / cheaper lessons & .137 & .004 & SC \\
\hline 5.You don't have to be a programmer to interact with machines. & .220 & .000 & SC \\
\hline 6. Interactive and insightful ICT-enabled learning. & .125 & .007 & SC \\
\hline 7. Email is an effective way for teacher and student to communicate. & .099 & .026 & SC \\
\hline 8. Social networking is an important way of teaching and learning connectivity. & .096 & .030 & SC \\
\hline 9. The computer / internet is easy to use to study. & .103 & .022 & SC \\
\hline 10. ICTs improve research incentive. & .070 & .084 & NSC \\
\hline 11. ICT makes my classes more appealing. & .057 & .132 & NSC \\
\hline 12.ICT leads to increasing my productivity. & .097 & .029 & SC \\
\hline 13.For my research, ICT is inexpensive. & .027 & .299 & NSC \\
\hline Overall & .150 & .002 & SC \\
\hline
\end{tabular}

Legend: NSC-No significant correlation; SC- With significant negligible correlation

\section{Conclusions and Implications}

Fresh and younger HEI college students are regularly introduced to ICTs and devices used in school. This ensures that ICT-based schooling will quickly be embraced and adjusted as the school system for the coming years.

School graduates in recent and younger HEIs are equipped for ICT-based learning as they do not have structured instruction and experience in ICT or in coding utilizing their own internet-connected devices at home. At least once a week, they use machines. They are allowed to use technology if machines and ICT are simpler to use at school. Schools will also invest in ICT and technology to inspire the students further.

Therefore, current and younger HEI university students embrace and approve of all facets of ICT-based education as the new landscape in the Philippines and Asia of the new millennium. This will therefore inspire new and younger HEIs not to retain ICT as an alternative, but as a must for their education system. It is also important for ICT to be completely incorporated into the education structure of new and younger HEIs.

Male college students are more optimistic than female students in terms of ICT employment. Therefore, HEIs will offer any student equal opportunities for access and meeting ICTs and computers irrespective of gender.

Internet access affects students 'mindset towards ICT and computers in school. New and younger HEIs will therefore spend the effort and facility to allow Internet access for all school students via wifi or some kind of networking to encourage university students 'attitudes to ICT-based learning.

Because machine access generates a positive attitude towards ICT-based education, the full integration of ICT into curricula of all fresh and younger HEIs who are not yet in the curriculum should be achieved. It helps to improve students 'access to ICT and ICT instruction. 


\section{$5 \quad$ References}

[1] www.computer.org/csdl/mags/co/2010/11/mco2010110020.html on March 4, 2013.

[2] Baggaley, Jon and Belawati, Tina (2010). Distance education technologies in Asia. New Delhi: Sage Publications. Pradhan, G. (2003a). Bhutan digital review of Asia Pacific. 2003-04. Penang: Southbound.

[3] http://www.computerorg/csdl/mags/co/2010/11/mco2010110020.htmlon July 12, 2013).

[4] Kozma, Robert B. (2010) Education policy: ICT and transformative education policy. INTEL.

[5] Roblyer, M.D. and Doering, Aaron H. (2013). Integrating educational technology into teaching, Sixth edition. Boston: Pearson.

[6] Jamtsho, S. and Bullen, M. (2007). Distance education in Bhutan: Improving access and quality through ICT use. Distance education, 28(2), 149-161. Sangi, N. and Ahmed, M. (2007). E-learning initiatives at AIOU: A case study of using ICT in education. 1st Elearning and distance education conference, Lahore, Pakistan. https://doi.org/10.1080/ 01587910701439217

[7] Barrow, Lisa; Markman, Lisa; and Rouse, Cecilia Elena (2009). Technology's edge: The educational benefits of computer-aided instruction. American Economic Journal. 1(1): 5274. https://doi.org/10.3386/w14240

[8] Pradhan, G. (2003a). Bhutan digital review of Asia Pacific. 2003-04. Penang: Southbound. Zhang, Jianwei. (2004). Using ICT to prepare learners for the 21 st century: The perspectives of the eastern APEC economies. China: Educational Technology Center, Tsinghua University.

[9] Coleman, Alfred. (2012). "Towards delivering e- health education using Public Internet Terminals (PIT) systems in rural communities in south Africa." JCOM: Journal of Science Communication 11.4 (2012). Retrieved (5 June 2013) from URL http://gogalegroup.com/ps/i.do?idGALE7CA315370845\&v2.1\&uphtrialgrp\&itr\&p GPS\&sww https://doi.org/10.22323/2.11040201

[10] Ali, Mohammad. (2003). Bangladesh ICT case study: ASPBAE research on information and communication technology. Bangladesh: Asian South Pacific Bureau of Adult Education.

\section{Authors}

Yamunah Vaicondam is a Faculty of Business, Social Science \& Hospitality,Segi University, Kota Damansara, 47810 Petaling Jaya, Selangor, Malaysia. Email: yamunahvaicondam@segi.edu.my

Sanil S Hishan Azman Hashim International Business School (AHIBS), Universiti Teknologi Malasia, Malaysia

Samina Begum is an Assistant Professor at Abbottabad University of Science and Technology. Email: dr_samina@yahoo.com

Muhammad Hassan is a Lecturer at Department of Management Sciences,Abbottabad University of Science and Technology, Pakistan, and a PhD Candidate at Faculty of Business, Economics \& Social Development, Universiti Malaysia Terengganu, Malaysia. Email: hassan@aust.edu.pk

Article submitted 2020-12-07. Resubmitted 2021-01-15. Final acceptance 2021-01-16. Final version published as submitted by the authors. 